\title{
Facebook as a tool for communication, collaboration, and informal knowledge exchange among members of a multisite family health team
}

This article was published in the following Dove Press journal:

Journal of Multidisciplinary Healthcare

25 January 2016

Number of times this article has been viewed

\author{
Aisha K Lofters ${ }^{1,2}$ \\ Morgan B Slater \\ Emily Nicholas Angl' \\ Fok-Han Leung' \\ 'Department of Family and \\ Community Medicine, ${ }^{2}$ Centre for \\ Research on Inner City Health, \\ Li Ka Shing Knowledge Institute, \\ St Michael's Hospital, University \\ of Toronto, Toronto, ON, Canada
}

Correspondence: Aisha K Lofters Department of Family and Community Medicine, St Michael's Hospital, 30 Bond Street, Toronto, ON M5B IW8, Canada

Tel +l 4I6867 7428

Email aisha.lofters@utoronto.ca
Objective: To implement and evaluate a private Facebook group for members of a large Ontario multisite Family Health Team (FHT) to facilitate improved communication and collaboration. Design: Program implementation and subsequent survey of team members.

Setting: A large multisite FHT in Toronto, Ontario.

Participants: Health professionals of the FHT.

Main outcome measures: Usage patterns and self-reported perceptions of the Facebook group by team members.

Results: At the time of the evaluation survey, the Facebook group had 43 members $(37.4 \%$ of all FHT members). Activity in the group was never high, and posts by team members who were not among the researchers were infrequent throughout the study period. The content of posts fell into two broad categories: 1) information that might be useful to various team members and 2) questions posed by team members that others might be able to answer. Of the 26 team members $(22.6 \%)$ who completed the evaluation survey, many reported that they never logged into the Facebook page (16 respondents), and never used it to communicate with team members outside of their own site of practice (19 respondents). Only six respondents reported no concerns with using Facebook as a professional communication tool; the most frequent concerns were regarding personal and patient privacy.

Conclusion: The use of social media by health care practitioners is becoming ubiquitous. However, the issues of privacy concerns and determining how to use social media without adding to provider workload must be addressed to make it a useful tool in health care.

Keywords: social media, team-based care, communication, interprofessionalism, social network

\section{Background}

Ontario's Ministry of Health and Long-Term Care has invested heavily in the creation of Family Health Teams (FHTs) in Ontario, with >150 FHTs currently in existence. These FHTs are expected to provide high-quality, accessible, and multidisciplinary primary care, with teamwork, collaboration, quality improvement, and patient-centered care being key components. ${ }^{1}$ Although some FHTs are housed at a single site, $~ 60 \%$ of Ontario FHTs surveyed in 2012 had at least two sites. ${ }^{2}$ Although there are certain benefits of an FHT having large numbers of team members dispersed over multiple sites, this geographic separation has also been thought to impede FHT development in some ways, and encourage providers to work in silos. ${ }^{3}$

Social networking sites, or social media, are virtual communities where users can create individual profiles and interact with others. ${ }^{4,5}$ Online social networking sites provide a relatively innovative and potentially convenient way for users to communicate 
and establish and maintain connections with others based on virtual groups of their choice. The design and interactive nature of these sites may make them more palatable for these uses than mass emails. Social media has been associated with bridging social capital, where users provide useful information or new perspectives for one another, and has been used in health care to disseminate health information, provide information on available local resources, publicize educational events, and receive feedback from colleagues. ${ }^{6-8}$ Online physician communities have been used with success for educational purposes, for consulting on patient issues, and for discussing professional challenges. ${ }^{9}$ In one US study of physicians, $24.1 \%$ of respondents used social media daily to explore medical information. ${ }^{10}$

Facebook is likely the most popular social networking site and is currently free to use and user-friendly. It is also widely accessed among physicians for personal use. ${ }^{9}$ Its use has been associated with bridging social capital and with the concept of social mobilization, which views a group of people as a distributed knowledge resource that can be tapped. ${ }^{6,11}$ Organizations can create both pages and groups in Facebook. Although pages allow for some level of analytics through the Facebook site, groups have administrators and allow for more stringent privacy settings. Therefore, the overarching objective of this pilot study was to implement and evaluate a private Facebook group for members of a large Ontario multisite FHT to facilitate improved communication and collaboration. Specific objectives were 1) to implement a private Facebook group for members of a large Ontario multisite FHT to facilitate communication and collaboration, and 2) to evaluate the usage patterns and perceptions of the Facebook group by FHT members.

\section{Methods}

\section{Setting}

The study took place within an FHT in Toronto consisting of $\sim 115$ team members, including family physicians, nurses, nurse practitioners, dieticians, psychologists, social workers, chiropractors, health promoters, and other health professionals. The FHT is spread out across four geographically distinct sites, with patients and providers generally being based at one home site. All sites use one electronic medical record (EMR) system. A previous survey of providers at our $\mathrm{FHT}^{12}$ conducted as part of a preimplementation work indicated that only $54 \%$ agreed that they were aware of the resources and services offered within the FHT but outside of their home site, and $68 \%$ agreed that communication with the FHT was negatively affected because of the geographic distribution of sites. A majority of respondents (61\%) agreed that social media could improve communication among team members. ${ }^{12}$

\section{Implementation}

The logic model displayed in Figure 1 depicts the inputs, outputs, and desired outcomes of the Facebook initiative. The goal was to create a private Facebook group that would provide a virtual venue for users to ask each other clinically related questions (eg, medication suggestions), post information about themselves and the services they provide, find others within the FHT who provided specialized patient services (eg, obstetrics), share information on intra- and

\begin{tabular}{|c|c|c|}
\hline $\begin{array}{l}\text { Inputs (what } \\
\text { is invested) }\end{array}$ & $\begin{array}{c}\text { Outputs } \\
\text { (what is done) }\end{array}$ & $\begin{array}{c}\text { Desired } \\
\text { outcomes }\end{array}$ \\
\hline $\begin{array}{l}\text { Preimplementation } \\
\text { survey findings } \\
\text { Research team } \\
\text { Facebook platform } \\
\text { Group } \\
\text { administrator } \\
\text { Input from FHT } \\
\text { members on how } \\
\text { to best use the } \\
\text { Facebook group }\end{array}$ & $\begin{array}{l}\text { Presentations at staff and team } \\
\text { meetings conducted } \\
\text { Facebook group guide created } \\
\text { Facebook group privacy } \\
\text { settings guide created } \\
\text { Internal social media guidelines } \\
\text { created } \\
\text { One-on-one training sessions } \\
\text { offered } \\
\text { Individual team member profiles } \\
\text { created, facilitated by group } \\
\text { administrator }\end{array}$ & $\begin{array}{l}\text { Short-term } \\
\text { Improvement in communication } \\
\text { among FHT members } \\
\text { Medium term } \\
\text { Improvement in patients' access to } \\
\text { FHT services } \\
\text { Reduction in external referrals } \\
\text { Long-term } \\
\text { More efficient quality care for } \\
\text { patients }\end{array}$ \\
\hline & $\begin{array}{l}\text { Different team members } \\
\text { profiled on a regular basis }\end{array}$ & \\
\hline
\end{tabular}

Figure I Logic model describing implementation of a private Facebook group for a Family Health Team in Ontario. Abbreviation: FHT, Family Health Team. 
extra-FHT resources, share new-found clinical information (eg, guideline updates), and update team members on various activities and events.

\section{Inputs}

Prior to launching the group, members of the FHT were invited to an informal session to discuss how best to make use of the group and any concerns they had about using the Facebook platform. Suggestions from this session with six team members (both physicians and nonphysicians) included profiling different team members on a regular basis, avoiding posts about media health stories, keeping posts relevant to FHT issues, focusing on posts that sparked conversation or debate, and creating a separate professional Facebook profile if team members already had a personal profile.

\section{Outputs}

At various staff meetings where the initiative was presented, it was emphasized that the private nature of the Facebook group meant that only professionals who worked as part of the FHT would be approved for membership in the group. Group membership had to be authorized by one of the researchers. Upon launch of the group, supporting documents were distributed to all FHT members, namely, a general guide on Facebook use, a guide on ensuring stringent privacy settings, and the College of Physicians and Surgeons of Ontario guidelines on professionalism in use of social media. ${ }^{13}$ One-on-one training sessions were offered to team members who wanted assistance in setting up their profiles. In addition, one of the researchers (EN) made frequent site visits to remind team members about the group and to provide face-to-face educational outreach. A template for setting up a profile, including describing one's profession and particular skills/interests, was sent to each new member upon joining, and a researcher (EN) was available to facilitate profile creation. She also regularly wrote detailed posts that profiled team members who were part of the Facebook group, with an emphasis on nonphysicians. These posts were meant to highlight health professionals whose team members at other sites might not be aware of and to describe their experience and expertise.

\section{Desired outcomes}

In the short-term, we anticipated that the Facebook group could improve communication among FHT members. This increased communication could subsequently lead in the medium term to improvement in patients' access to services regardless of the home site and a reduction in external referrals for services where expertise existed within the FHT.
As quality improvement and patient-centered care are key pillars of Ontario's FHTs, we hypothesized that improved communication could ultimately lead to more efficient quality care for patients in the long-term. For this study, we aimed only to measure our desired short-term outcome.

\section{Evaluation}

We evaluated the usage patterns and perceptions of the Facebook group by FHT members as measures of our desired short-term outcome. In October 2014, an anonymous electronic survey, housed on FluidSurveys ${ }^{\mathrm{TM}}$, was distributed to all team members. The survey included questions about demographics, patterns of formal and informal communication, patterns of use of the Facebook group, the perceived benefits and harms, and suggestions for improvement.

Descriptive statistical analyses of the survey results were conducted using SAS version 9.4 (SAS Institute Inc., Cary, NC, USA). Usage patterns of the Facebook group were assessed by the number of members (provided by the Facebook site) and by manual tabulation of the number of unique posts per month, stratified into those by the researchers and those by others.

This study received approval from the St Michael's Hospital Research Ethics Board. Participants did not provide written informed consent. Consent was implied by completion of the survey. This method was approved by the St Michael's Hospital Research Ethics Board.

\section{Results Usage patterns}

By the time the survey was conducted, the Facebook group had 43 members (37.4\% of FHT members). However, activity in the group was never high, and levels of use dropped further after the employment contract of the researcher (EN) was completed in May 2014. Figure 2 depicts the number of posts on a monthly basis, stratified by posts by the researchers and by other members of the FHT. Posts by other FHT members were infrequent throughout the study period, reaching a maximum of 13 posts for the month of October in 2013. The content of posts fell into two broad categories: 1) information that might be useful to various team members (eg, dates of upcoming prenatal classes), and 2) questions posed by team members that others might be able to answer (eg, local chiropody services for diabetic patients).

\section{Survey results}

A total of 26 FHT members $(22.6 \%$ of 115$)$ completed the survey (Table 1$)$. The majority $(73.1 \%)$ were physicians, and 


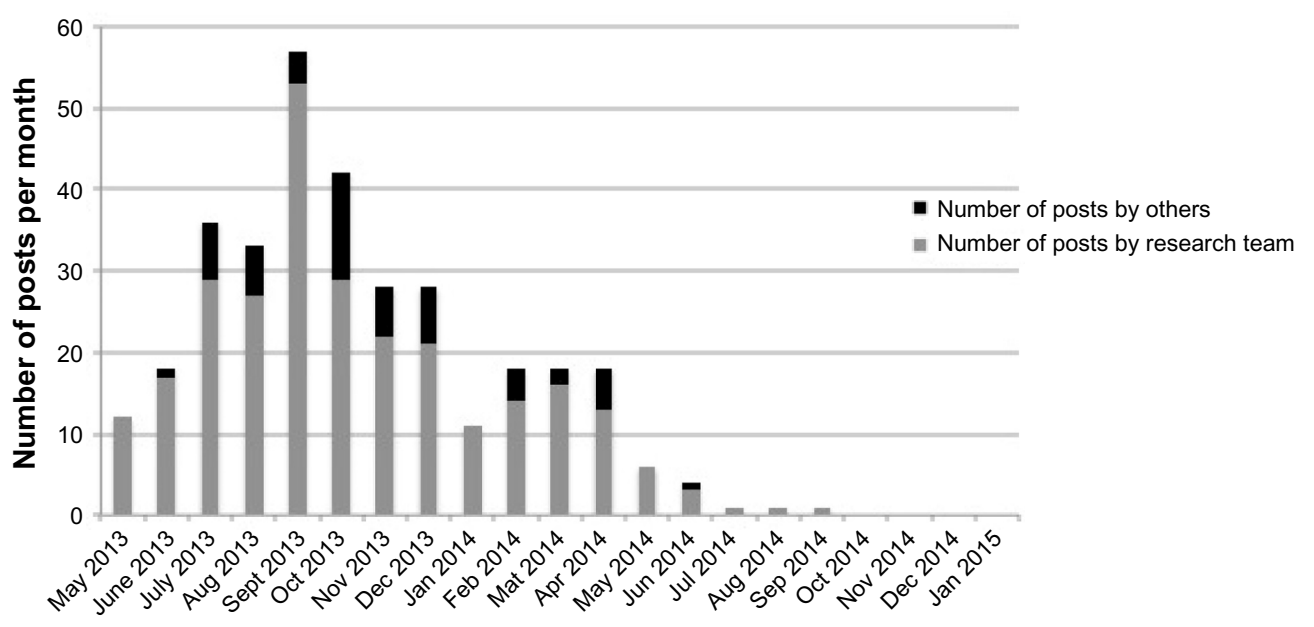

Figure 2 Number of posts per month by researchers and by other Family Health Team members among 43 persons registered to the Facebook group, from May 2013 to January 2015.

$46.2 \%$ were aged $\leq 40$ years old. More than half $(57.7 \%)$ had been with the FHT for $\leq 5$ years. While a large proportion of respondents reported personal use of various social media sites, including Facebook (13 respondents), Twitter (eight respondents), and LinkedIn (six respondents), and a majority of respondents agreed that social media could improve communication among FHT members (50.0\% agreed/strongly agreed), many reported that they never logged into the Facebook page (16 respondents) and never used it to communicate with FHT members outside of their own site of practice (19 respondents). Only six respondents reported no concerns with using Facebook as a professional communication tool. Among those who did have concerns, concerns for both personal and patient privacy were top of the list (Figure 3 ). When asked about other means of communication used by the FHT members at other sites for work-related issues, email was found to be most commonly reported (91.7\%), followed by use of the EMR messaging systems (87.5\%).

Table I Demographics of 26 survey respondents

\begin{tabular}{ll}
\hline Demographic & $\mathbf{n}(\%)$ \\
\hline $\begin{array}{l}\text { Role within the Family Health Team } \\
\text { Physician }\end{array}$ & $19(73.1)$ \\
$\quad$ Other health professional & $7(26.9)$ \\
Years of experience in current role & \\
$\leq 5$ years & $15(57.7)$ \\
$5+$ years & $11(42.3)$ \\
Age & \\
$\leq 40$ years & $12(46.2)$ \\
$\geq 4$ I years & $8(30.8)$ \\
Did not answer & $6(23.1)$ \\
Sex & \\
Male & $6(23.1)$ \\
Female & $12(46.2)$ \\
Other/preferred not to answer/did not answer & $8(30.8)$ \\
\hline
\end{tabular}

Open-ended questions allowed respondents to suggest ways to improve communication between sites. Of seven suggestions submitted, five involved either more meetings or more effective meetings and two involved establishing a fully functional FHT website.

\section{Discussion}

In this study, we found that after 1 year of use, the implementation of a private Facebook group for a large, multisite FHT was ultimately not successful, despite cross-site communication having previously been identified to be in need of improvement by FHT members. ${ }^{12}$ Use of the group depended heavily on the study team and was not sustained. Survey respondents expressed high levels of concern about both patient and provider privacy and viewed the Facebook group as unnecessary, adding extra time and work to their already busy days. Although our findings are limited by the fact that only $22.6 \%$ of FHT members completed the survey, their responses have face validity and respondents included both users and nonusers of the Facebook group.

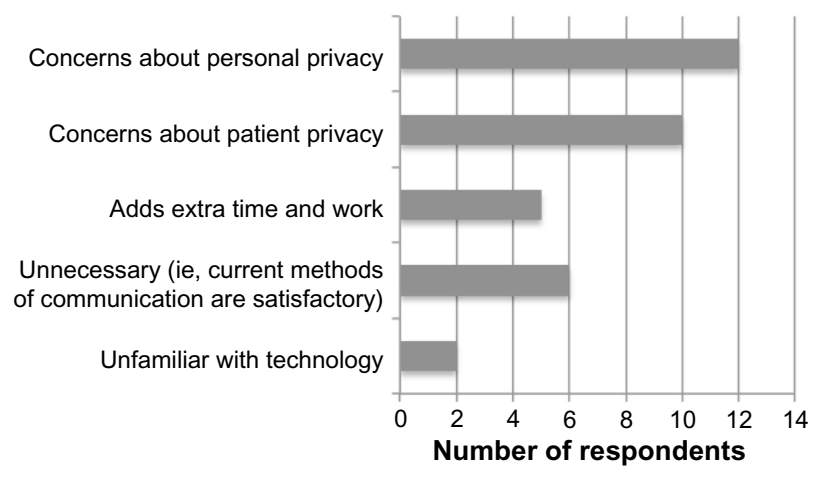

Figure 3 Self-reported concerns about using Facebook as a professional communication tool among 18 respondents who reported concerns. 
There were four key lessons learned on what would be needed to make an online communication program successful for a multisite FHT. First, buy-in and involvement from provider leaders is needed. One of the posts that inspired the most follow-up commentary was by a provider in a leadership role who had been part of the FHT for many years. Posts from the researchers (encompassing the majority of posts) did not have the same cachet. Second, a successful initiative would require a social media platform that providers trust. Our survey results suggest that FHT members were inherently suspicious of Facebook, even with guides on privacy settings in place and the recommendation to create a separate profile. Their fears were mimicked by an Australian study that found that close to $65 \%$ of physicians were hesitant to use social media intensely due to concerns about public access. ${ }^{14}$ Third, any mode of communication used would need to be fully integrated into the overall communication plan of the FHT. A fourth and related lesson was that any new communication method should be ideally integrated into existing electronic software systems to minimize the number of "clicks" required to participate.

There is a strong need for improving communication methods in today's health care environment, as evidenced by the interest expressed in our initiative from external groups, such as a major university medical education department, a university-affiliated hospital, and a hospital infection control team. However, considering the level of concern raised by our participants about the value added, privacy, and security in using the Facebook platform, future research should continue to investigate other innovative and affordable ways to increase communication between collaborating health professionals. Provider-only social networking sites hold promise. For example, the Doximity website, which is for physicians only, proclaims that $50 \%$ of US physicians have joined its network, however it is not organization specific and is currently available only in the USA. ${ }^{15,16}$ Yammer is an example of a social networking site used for private communication within organizations and has been used with great success in at least one other Ontario FHT for both intrateam communication and communication between patients and team members (Dr Sanjeev Goel, Wise Elephant FHT, email communication, February, 2015). ${ }^{17}$ A high level of functionality of the EMR has been shown to positively influence FHT climate and foster collaboration, suggesting that the exploration of EMR capabilities should also be a priority. ${ }^{1,3,18}$ The EMR was also commonly used among our survey respondents as a mode of cross-site communication.

Team-based care continues to take hold in primary care in Canada and with good reason. The team approach in primary care has been used successfully to address chronic disease management and prevention and to improve patient health status $^{19}$ and emphasizes a focus on quality improvement. With many FHTs spread out geographically, challenging their ability to work effectively as a team, ${ }^{3,20}$ team members must work actively to develop a sense of cohesion. Face-to-face communication, such as through the hallway consult, has been found to be the method of choice for issues related to patient care among primary care teams, but it is not always possible for larger teams. ${ }^{18}$ Methods such as regular inperson meetings, interprofessional work groups, and team retreats have all been used by FHTs with some success, ${ }^{3}$ but they still do not address all issues inherent in geographic separation.

The use of social media by health care practitioners is becoming ubiquitous, as evidenced by the many guidelines developed in recent years around social media and professionalism and the many resources discussing social media use by health professionals. ${ }^{13,15,21-30}$ However, the issues of privacy concerns and determining how to use social media without adding to provider workload must be addressed to make it a useful tool in health care. Accordingly, the current use of Facebook and other social media sites by other primary care and health care groups to create virtual communities of practice should continue to be monitored over time to assess for success, sustainability, effects on quality of care, and lessons learned. ${ }^{7,31}$

\section{Disclosure}

The authors have no conflicts of interest in this work.

\section{References}

1. Howard M, Brazil K, Akhtar-Danesh N, Agarwai G. Self-reported teamwork in family health team practices in Ontario: organizational and cultural predictors of team climate. Can Fam Physician. 2011;57(5): e185-e191.

2. Mcmurchy D, Palmer R, Prada G, Astles P. An External Evaluation of the Family Health Team (FHT) Initiative. Ottawa, ON: The Conference Board of Canada; 2014.

3. Goldman J, Meuser J, Rogers J, Lawrie L, Reeves S. Interprofessional collaboration in family health teams: an Ontario-based study. Can Fam Physician. 2010;56(10):e368-e374.

4. Wegmann E, Stodt B, Brand M. Addictive use of social networking sites can be explained by the interaction of internet use expectancies, internet literacy, and psychopathological symptoms. J Behav Addict. 2015;4(3):155-162.

5. Meshi D, Tamir DI, Heekeren HR. The emerging neuroscience of social media. Trends Cogn Sci. 2015;19(12):771-782.

6. Ellison NB, Steinfield C, Lampe C. The benefits of Facebook "friends": social capital and college students' use of online social networking sites. J Comp Med Commun. 2007;12(4):1143-1168.

7. Khan H. How One CCG is Using Facebook to Improve Communication. The Guardian; 2012. Available from: http://www.theguardian.com/ healthcare-network/2012/nov/22/ccg-facebook-social-media-doctors. Accessed December 15, 2015.

8. Santy J, Beadle M, Needham Y. Using an online case conference to facilitate interprofessional learning. Nurse Educ Pract. 2009;9(6):383-387. 
9. Modahl M, Tompsett L, Moorhead T. Doctors, Patients and Social Media. Massachusetts: Care Continuum Alliance; 2011.

10. McGowan BS, Wasko M, Vartabedian BS, Miller RS, Freiherr DD, Abdolrasulnia M. Understanding the factors that influence the adoption and meaningful use of social media by physicians to share medical information. J Med Internet Res. 2012;14(5):e117.

11. Six Degrees of Mobilisation. The Economist. 2012. Available from: http://www.economist.com/node/21560977. Accessed February 12, 2015.

12. Slater M, Nicholas E, Leung FH, et al. Communication and knowledge exchange within a large, academic family health team. CFP. In press 2016.

13. The College of Physicians and Surgeons of Ontario. [webpage on the Internet]. Social Media - Appropriate Use by Physicians. Available from: http://www.cpso.on.ca/policies/positions/default.aspx?id=7874. Accessed January 28, 2015.

14. Brown J, Ryan C, Harris A. How doctors view and use social media: a national survey. J Med Internet Res. 2014;16(12):e267.

15. Digitome. [webpage on the Internet]. Physician Social Networks. Available from: http://digito.me/physician-social-networks/. Accessed January 22, 2015.

16. Doximity. [homepage on the Internet]. Physician's Network and Healthcare Directory. Available from: https://www.doximity.com. Accessed January 28, 2015.

17. Yammer. [homepage on the Internet]. The World Moves Fast. Move Faster with Yammer. 2015. Available from: https:// www.yammer.com. Accessed February 4, 2015.

18. Brown JB, Lewis L, Ellis K, Stewart M, Freeman TR, Kasperski MJ. Mechanisms for communicating within primary health care teams. Can Fam Physician. 2009;55(12):1216-1222.

19. Barrett J, Curran V, Glynn L, Godwin M. Synthesis: Interprofessional Collaboration and Quality Primary Healthcare. CHSRF, Ottawa, ON: Canadian Health Services Research Foundation; 2007.

20. Goldman J, Meuser J, Lawrie L, Rogers J, Reeves S. Interprofessional primary care protocols: a strategy to promote an evidence-based approach to teamwork and the delivery of care. J Interprof Care. 2010; 24(6):653-665.
21. Dr Wes. [webpage on the Internet]. Fisher W. Physician Blogger Insights on Social Media. Available from: http://drwes.blogspot. ca/2013/05/physician-blogger-insights-on-social.html. Accessed January 22, 2015.

22. American Academy of Family Physicians. [webpage on the Internet]. Social Media for Family Physicians. Available from: http://www.aafp. org/about-site/about/contact/updates/social-media.html. Accessed January 22, 2015.

23. Ohio Academy of Family Physicians. [webpage on the Internet]. Social Media. Available from: http://www.ohioafp.org/news-publications/ social-media/. Accessed January 22, 2015.

24. Royal College of General Practioners. [webpage on the Internet]. Social Media Highway Code. Available from: http://www.rcgp.org.uk/socialmedia. Accessed January 22, 2015.

25. Farnan JM, Snyder Sulmasy L, Worster BK, et al. Online medical professionalism: patient and public relationships: policy statement from the American College of Physicians and the Federation of State Medical Boards. Ann Intern Med. 2013;158(8):620-627.

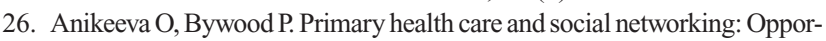
tunities to enhance communication. RESEARCH ROUNDup Issue 20. Adelaide: Primary Health Care Research and Information Service. 2011. Available from: http://www.phcris.org.au/publications/researchroundup/ issues/20.php. Accessed January 28, 2015.

27. news@JAMA. [wepage on the Internet]. Kuehn BM. Think Before You Tweet, E-mail, or Post to Online Groups, Advise Physicians. 2013. Available from: http://newsatjama.jama.com/2013/04/12/thinkbefore-you-tweet-e-mail-or-post-to-online-groups-advise-physicians/. Accessed January 28, 2015.

28. Hackworth BA, Kunz MB. Health care and social media: building relationships via social networks. Acad Health Care Manag J. 2010;6(1).

29. Prasanna PM, Seagull FJ, Nagy P. Online social networking: a primer for radiology. J Digit Imaging. 2011;24(5):908-912.

30. Hewlett-Packard Development Company. Healthcare White Paper. Social Media in Healthcare. Hewlett-Packard Development Company; 2013.

31. Barnett S, Jones SC, Caton T, Iverson D, Bennett S, Robinson L. Implementing a virtual community of practice for family physician training: a mixed-methods case study. $J$ Med Internet Res. 2014;16(3):e83.
Journal of Multidisciplinary Healthcare

\section{Publish your work in this journal}

The Journal of Multidisciplinary Healthcare is an international, peerreviewed open-access journal that aims to represent and publish research in healthcare areas delivered by practitioners of different disciplines. This includes studies and reviews conducted by multidisciplinary teams as well as research which evaluates the results or conduct of such teams or

\section{Dovepress}

healthcare processes in general. The journal covers a wide range of areas and welcomes submissions from practitioners at all levels, from all over the world. The manuscript management system is completely online and includes a very quick and fair peer-review system. Visit http://www.dovepress.com/testimonials.php to read real quotes from published authors. 